\title{
Study on identification method of tight sand gas and water in the Su54 Region of Sulige gas fileld
}

\author{
Fan Ping ${ }^{1,2, a}$,Zhang $\mathrm{Ji}^{1,2, b}$,Tan Hongqi ${ }^{3, \mathrm{c},}$, Duan Zhiqiang ${ }^{1,2}$, Liu Zhiheng $^{1,2}$, \\ Huang Qiangdong ${ }^{1,2}$, Luo han $^{4, *}$ \\ ${ }^{1}$ Research Center of Sulige Gasfield, Changqing Oilfield of CNPC, Xian 710000, China; \\ ${ }^{2}$ National Engineering Laboratory for Exploration and Development of Low permeability Oil \& Gasfield; \\ ${ }^{3}$ PetroChina International Iraq FZE, Beijing 100120, China. \\ ${ }^{4}$ Chongqing University of Science and Technology, Chongqing 410000, China. \\ a fanp_cq@petrochina.com.cn, ${ }^{\mathrm{b}}$ zhangji_cq@petrochina.com.cn, ${ }^{\mathrm{c}}$ tanhongqi@cnpcint.com
}

Keywords: Sulige gas fileld; Tight sandstone; low resistivity gas reservoir; gas and water identification.

\begin{abstract}
The phenomenon of "low-resistivity" gas reservoir and "high-resistivity" water reservoir exist side by side, rapid changes of longitudinal resistivity of the water reservoir and gas and water mixed reservoir in the Su 54 area of Sugeli gas field which caused gas-water identification difficulty. First, the genesis of low-resistivity gas reservoir in tight sand had been analysed. And then, the crossplot acoustic-resistivity method, multiple discriminant analysis method and support vector machine method had been used on gas-water identification method in research. Finaly, the gas testing and production dynamic data had been used to verify. The study results show that: the additional conductivity of clay minerals in tight sand reservoir and mud invasion is the main reason for the low-resistivity gas reservoir. And the three gas-water identification methods based on gas testing and production dynamic data made a better recognition effect in practical application; especially the gas-water recognition precision of support vector machine method reaches $93 \%$. This study provides a new thought for the gas-water identification of tight sand gas reservoir.
\end{abstract}

\section{Introduction}

Sulige gas field located in the northern Ordos Basin, the main reservoir for the tight sandstone reservoir under a large braided river delta sedimentary environment (He8 segment and Shan1 segment). Due to the abundance of low porosity and permeability reservoir heterogeneity stronger, becoming onshore unconventional gas exploration and development difficulties [1]. Especially Western Sulige gas field, in the low part of the overall structure, while wide cover type of hydrocarbon expulsion, filling capability strength, effective size, the combined effects of the strong heterogeneity of sand body development, resulting in the area of the well points gas-water complex relationship [2-5]. While water reservoirs logging response characteristics indicate that the study area low resistivity gas reservoir and the "high resistance" coexist water layer, the water layer resistivity change longitudinal section features complex, gas and water mixed storage, no air-water interface, logging gas the aqueous layer is difficult to identify.

Domestic and foreign scholars in tight sandstone gas reservoirs water recognition has been studied various methods, focused on: petrophysical properties identification method, log overlap method, a combination of logging parameters analysis, nuclear magnetic resonance logging calculation method AI calculation(Hamada G.M.,2000; Feng Chunzhen etc,2004;Liu Hongqi,2004;Tan Maojin etc,2011;Fu Chendong,2011) [6-10]. In this paper,based on previous studies on integrated application logging, test gas, production dynamics and core analysis data,conduct causes of low resistivity gas reservoir analysis, and use of sound waves-resistivity intersection method, multivariate discriminant analysis and support vector machine methods of tight sandstone reservoir of gas-water layer integrated identification, validity and applicability of the final verification methods. 


\section{Regional geological background}

Su-54 block is located in the northern West Sulige gas field, located in the territory Etuokeqi, regional structure under the Ordos Basin in northwestern Yishan slope, west Tianhuan depression, the block area of approximately $1821 \mathrm{~km} 2$. The block is lithic quartz sandstone special low porosity and low permeability tight gas reservoirs, construct a whole was east to the west, north and south central low upward trend in high-ends structure, vertical multi-stage stacked on sand, but reservoir tight, effective reservoir relative isolation and dispersed. The overall performance of the well points and scattered, and the aqueous layer bit more but uneven. With the deepening of field development, gas production water has seriously affected the development effect of the block. Therefore, research is urgently needed to identify the block gas and water, gas and water distribution to find out on this basis, build capacity screening favorable target area, lay the foundation for efficient construction blocks production.

\section{Causes of low resistivity gas reservoir}

Effects of clay minerals.Lithology and interstitial material(clay mineral)determines the type of reservoir porosity and pore structure characteristics. The finer the general lithology, the higher the clay content, causing the pore structure becomes complicated, and montmorillonite, illite clay mineral composition having high additional conductivity, so tight sandstone reservoir contains the clay minerals will lead to the emergence of low resistance gas reservoir phenomenon. According to Figure 2 SuA well $3577.8 \mathrm{~m}$ at the deep lateral logging resistivity value of only $17 \Omega \cdot \mathrm{m}$, but try to verify that the gas is gas reservoir interval, daily gas production is $4.18^{*} 10^{4} \mathrm{~m}^{3} / \mathrm{d}$, no water. SEM microscope observation, this layer segment portion illite filling pores filamentous growth form similar to the "bridge" mesh conductive system, leading to the emergence of low resistance gas reservoir.

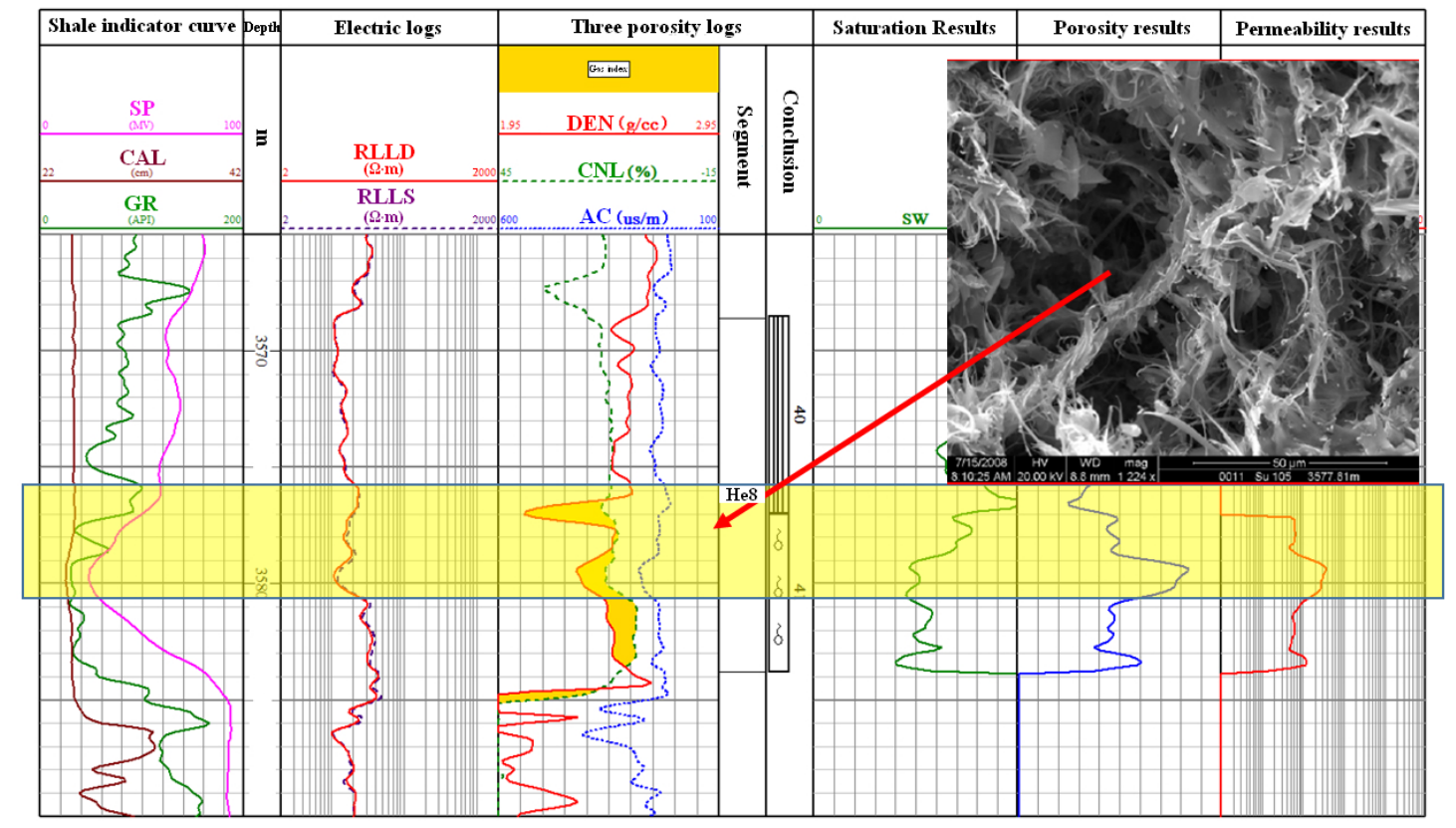

Figure 1. Low resistivity gas reservoir characteristics of SuA well

Effects of mud filtrate.To prevent the blowout, the borehole wall during drilling mud column pressure is slightly greater than the formation pressure, so the mud filtrate will permeate to the reservoir to form a cake in the wall. In the tight sandstone gas reservoirs, since gas is greater than the relative permeability formation water, mud filtrate radial penetration in the process, gas is expelled, resulting in the gas reservoir logging response characteristics influenced by mud invasion, the formation of low resistance. Analysts believe that the high porosity layer segment expulsion pressure is low, physical properties, good pore throat matching relationship, prone to deep mud filtrate invasion. Mud invasion of logging response characteristics were as follows: When the sonic 
difference increases, the density decreases, while the value did not change, or rather increased neutron, neutron excavation effect did not occur.
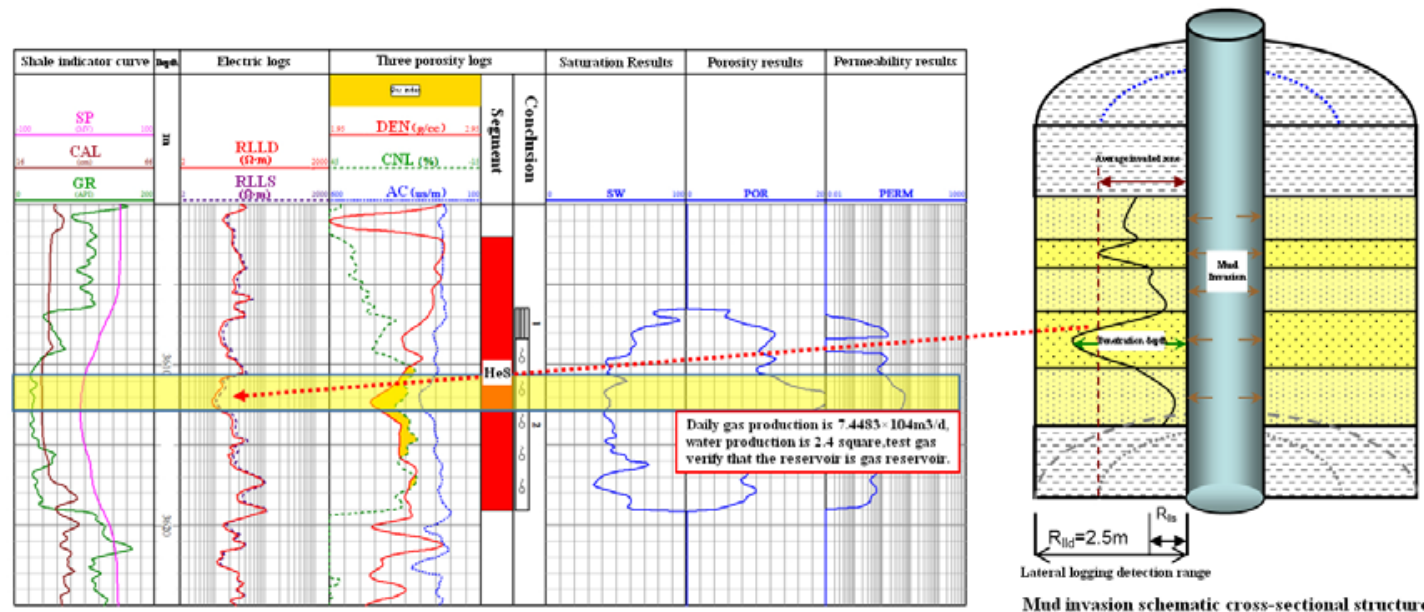

Figure 2. Mud invasion led to the emergence of low resistance gas reservoir characteristics of Su B Well

\section{Gas -water identification methods}

He8 segment: $\mathrm{RT}>7.45 \times 10^{5} / \mathrm{AC}^{2.41}$

Sample point $\mathrm{N}=45$

Shan1 segment: $\mathrm{RT}>8.0 \times 10^{5} / \mathrm{AC}^{2.41} \quad$ Sample pointN=61

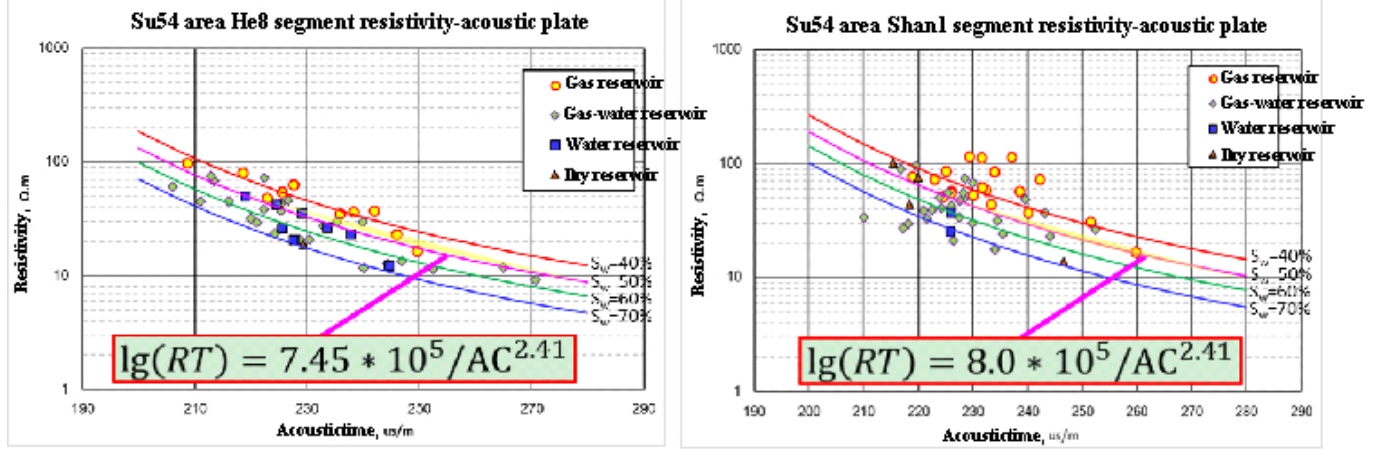

Figure 3. Su54 area subdivision plate method plate

Figure 4. SuC plate well $\mathrm{He}_{8}$ segment-Shan ${ }_{1}$ segment fine logging interpretation results figure

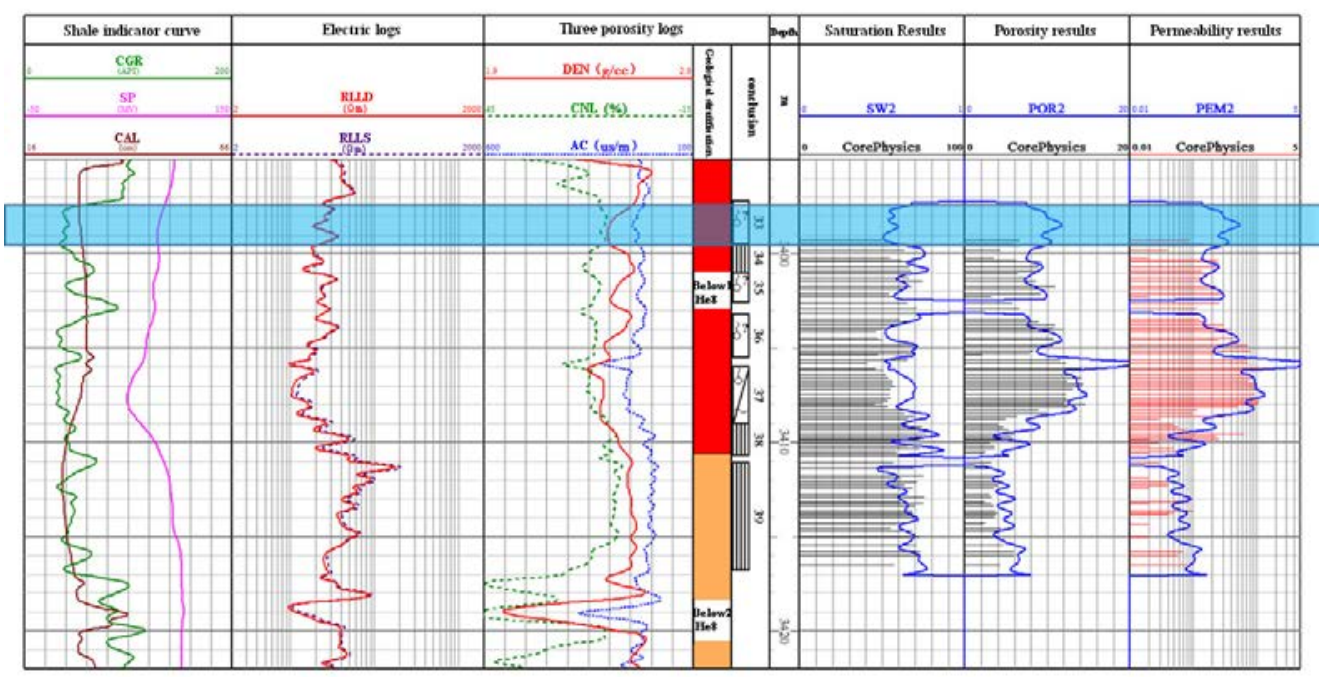

Figure 5. SuD well multivariate discriminant analysis result figure 


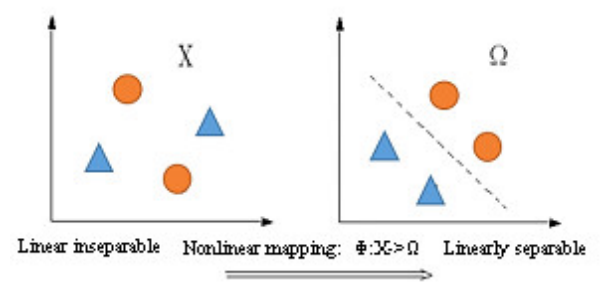

Optimal sorting line in case of linear separable Schematic SVM high-dimensional mapping feature

Figure 6. The basic idea of support vector machine

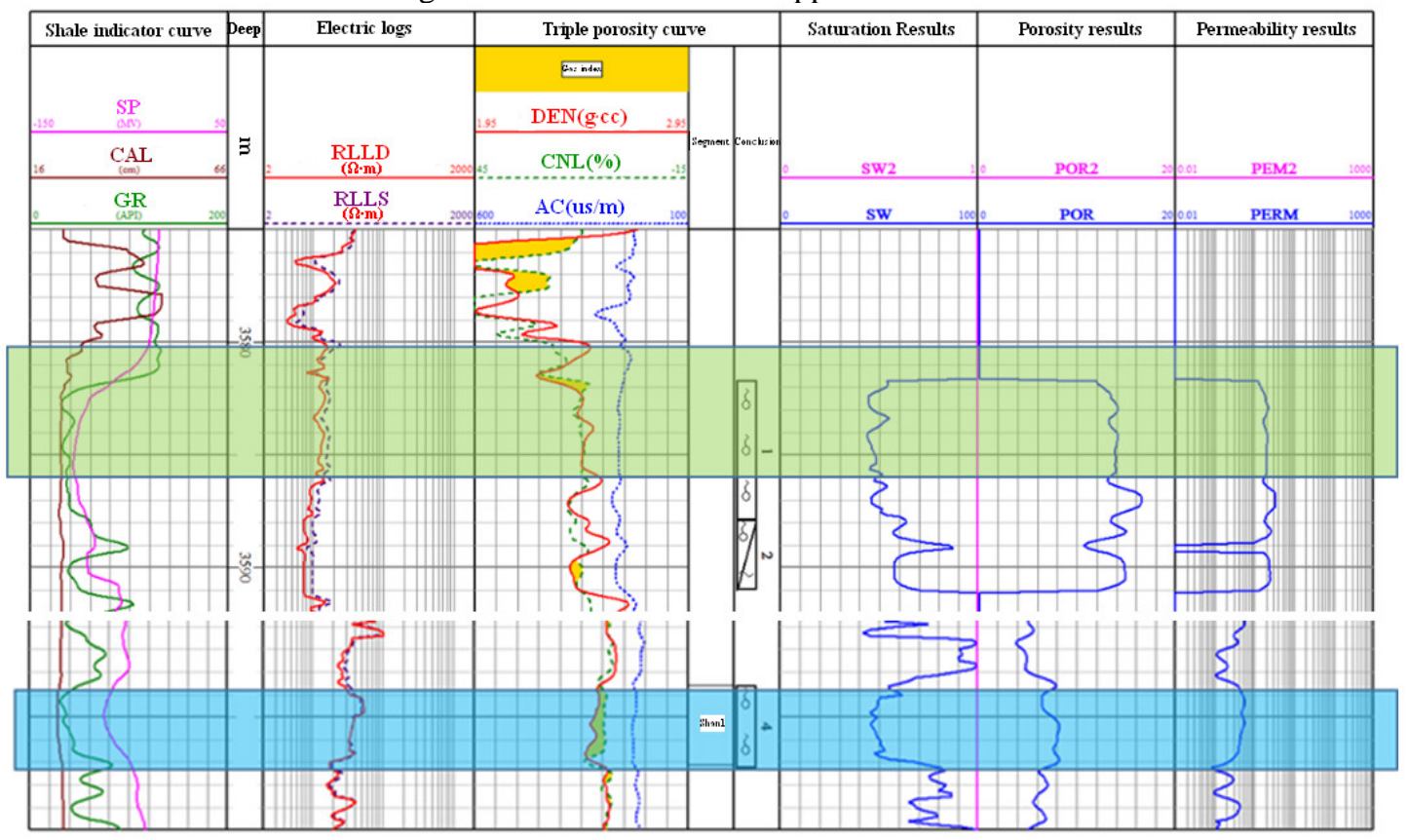

Figure 7. SuE well discriminating gas and water support vector machine instance figure

Table 1 . Su54 area support vector machine recognition results table

\begin{tabular}{|c|c|c|c|c|c|c|c|}
\hline Reservoir types & $\begin{array}{l}\text { The number of } \\
\text { positive sentence }\end{array}$ & $\begin{array}{l}\text { The number } \\
\text { of samples }\end{array}$ & Accuracy, $\%$ & Reservoir types & $\begin{array}{l}\text { The number of } \\
\text { positive sentence }\end{array}$ & $\begin{array}{l}\text { The number } \\
\text { of samples }\end{array}$ & Accuracy, $\%$ \\
\hline Dry reservoir & 0 & 1 & 0 & Dry reservoir & 3 & 4 & 75 \\
\hline Gas reservoir & 10 & 10 & 100 & Gas reservoir & 18 & 19 & 94.7 \\
\hline Gas-water reservoir & 25 & 25 & 100 & Gas-water reservoir & 27 & 27 & 100 \\
\hline Water reservoir & 5 & 7 & 71.4 & Water reservoir & 2 & 2 & 100 \\
\hline Total & 40 & 43 & 93 & Total & 50 & 52 & 96.2 \\
\hline
\end{tabular}

\section{Summary}

Fu Jin-hua,Wei Xin-shan,Ren Jun-feng.Distribution and genesis of large-scale Upper Palaeozoic lithologic gas reservoirs on Yi-Shaan Slope[J].Petroleum Exploration and Figure 2 is Mud invasion led to the emergence of low resistance gas reservoir characteristics of SuB Well. The well pressure between $\mathrm{He}_{8}$ segment coefficient of 0.9-0.8, using drilling mud weight average 1.06-1.08, the density difference between the average at about 0.36, calculated according to the average depth of $3500 \mathrm{~m}$, mud net residual pressure of about $12 \mathrm{MPa}$, this interval occurs mud invasion, leading to a lateral resistivity reducing gas layer depth, the magnitude of the difference is reduced.

Sonic-resistivity intersection method.Plate method is an empirical method uses single gas reservoir rendezvous point logging parameters to effectively identify gas reservoir and non-gas layer.Use the Archie formula , both sides can get logarithmic:

When is different, there are a bunch of parallel lines can pan up and down in the axial direction, wherein a, b, n, Rw control the shift amount, and m control the slope of the curve of the family, so that within a certain range of porosity.In exploratory single test data on the basis of the Soviet Union 54 district do acoustic-deep lateral resistivity-gas saturation intersection (Figure 3). With this chart you can see the resistance of the gas-water boundary layer is not fixed value, with increasing acoustictime 
and gas reservoir resistivity decreases.According to determine gas reservoir plate electrical standards:

Figure 4 is use the study of the sound waves - resistivity intersection SuC plate well $\mathrm{He}_{8}$ segment-Shan ${ }_{1}$ segment fine logging interpretation results figure.From top to bottom is divided into 1-8 small layer, in which the 2nd small layer deep lateral resistivity is $29.7 \Omega \cdot \mathrm{m}$, acoustictime is $239.9 \mu \mathrm{s} / \mathrm{m}$, the fourth layer deep small lateral resistance is $16.4 \Omega \cdot \mathrm{m}$, sonic the difference is $230.6 \mu \mathrm{s}$ / $\mathrm{m}$, the sixth small layer deep lateral resistivity is $20.9 \Omega \cdot \mathrm{m}$, acoustictime is $219.3 \mu \mathrm{s} / \mathrm{m}$, the fourth layers deep small lateral resistance is $23.0 \Omega \cdot \mathrm{m}$, acoustictime is $218.3 \mu \mathrm{s} / \mathrm{m}$. Use the chart to determine, the second layer conclusion is gas reservoir, No. 4,6,8 small gas-bearing layer is changed by a gas water layer, it’s improved the interpretation accuracy.

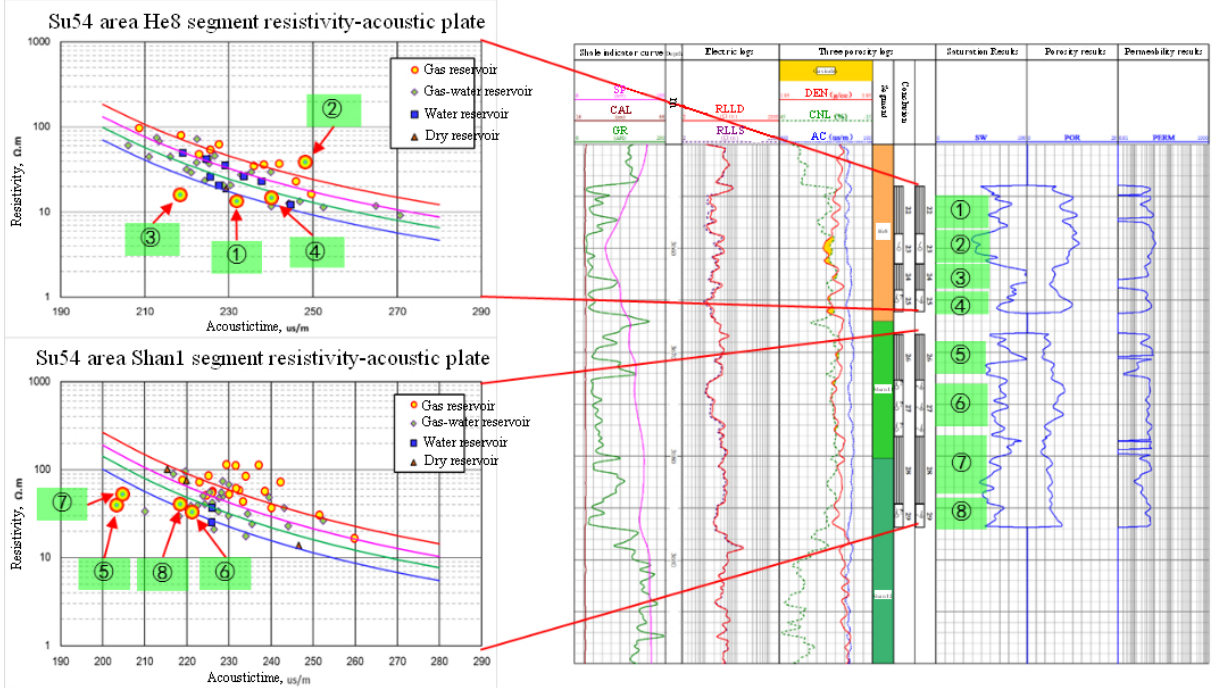

Multiple discriminant analysis.Multiple discriminant analysis is a statistical system statistical techniques for identification and classification of conduct. It can be given information on a certain number of individuals of a categorical variable and corresponding other multivariate determine the number of relations with other multivariate categorical variables between the established discriminant function, and finally the use of information on known multivariate discriminant function variables but unknown to discriminate grouping individual packets.

In exploratory single test results, based on the establishment of discriminant analysis of data tables. Among them, $\mathrm{He}_{8}$ segment has one sample of dry layer, 10 samples of gas layer, 25 samples of gas-water layer, 7 samples of water laye, Shan ${ }_{1}$ segment has 4 samples of dry layer, 19 samples of gas layer, 26 samples of gas-water layer, 2 samples of water layer.Selected discriminant variables include RT, AC, DEN, CNL, SH, SG. Establish discriminant equation is as follows of $\mathrm{He}_{8}$ segment:

Dry layer:3.049*RT+12.573*AC+4669.73*DEN-1.833*CNL-0.588*SH+1.871*SG-7364.378

Gas layer:3.224*RT+12.861*AC+4676.584*DEN-2.266*CNL-0.546*SH+2.073*SG-7460.538

Gas-water layer:

3.099*RT+12.628*AC+4660.389*DEN-1.998*CNL-0.551*SH+2.07*SG-7363.333

Water

layer:3.076*RT+12.611*AC+4670.075*DEN-1.887*CNL-0.579*SH+1.987*SG-7379.968

Establish discriminant equation is as follows of $\operatorname{Shan}_{1}$ segment:

Dry layer:1.079*RT+12.784*AC+3200.491*DEN-9.666*CNL-1.986*SH-0.391*SG-5408.282

Gas layer:1.016*RT+12.85*AC+3219.313*DEN-9.651*CNL-1.956*SH-0.076*SG-5483.453

Gas-water layer:

0.937*RT+12.737*AC+3226.768*DEN-9.721*CNL-1.921*SH-0.018*SG-5474.835

Water layer:

0.955*RT+12.754*AC+3225.524*DEN-10.018*CNL-2.066*SH-0.213*SG-5462.653

Figure 5 is a multivariate discriminant equations of gas and water to identify achievements diagram in which case layer $33 \mathrm{SuD}$ well of $\mathrm{He}_{8}$ segment explaining the conclusions of the original gas-bearing, the layer deep resistivity is $26.6 \Omega . \mathrm{m}$, acoustictime is $233.5 \mu \mathrm{s} / \mathrm{m}$, the density is 
$2.5 \mathrm{~g} / \mathrm{cm}^{3}$, natural gamma is $51.4 \mathrm{API}$, the porosity is $8.7 \%$, permeability is $0.432 \mu \mathrm{m}^{2}$, saturation is 43.6\%. After multivariate discriminant analysis, the determination result is an aqueous layer. The test gas segment, daily gas production is $0.1345 \times 10^{4} \mathrm{~m}^{3} / \mathrm{d}$, daily water production is $22.6 \mathrm{~m}^{3} / \mathrm{d}$.

Support vector machine.Support vector machine (Support Vector Machine, called SVM) is Vapnik et al statistical learning theory proposed the establishment of a small sample of statistical learning theory in VC dimension and structural risk minimization concept based on the principle.

The basic idea is to use the kernel function of the low-dimensional space can not be separated samples are mapped into a high dimensional feature space, find the optimal classification surface of the original samples in the feature space to obtain a linear input variables and output or non-linear relationship between the results that seek support vector pattern classification (Figure 6).

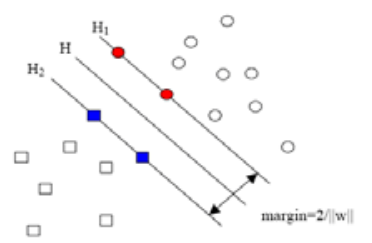

The main idea: to seek an optimal set of parameters to obtain training support vector machine classification test sample prediction accuracy rate is highest. In this study, k-fold cross-validation method to obtain a more stable prediction accuracy, the specific implementation process: the training data into k subsets (usually average), first with which the (k-1) subsets as the training to obtain a sample SVC, with the rest of the subset as a test set, test classification accuracy of the classifier. So $\mathrm{k}$ cycle times, until all subsets are used as the test sample is predicted again, eventually taking it k times the average prediction accuracy of the resulting value as the ultimate accuracy.

The main steps: (1) using standard deviation normalization methods such as logging parameters normalized; (2) using principal component analysis of the logging parameters for dimension reduction.

Optimization Methods: (1) based parametric grid search method is preferable; (2) parameter optimization based on genetic algorithms; (3) based on particle swarm algorithm parameter optimization.

Figure 7 is a support vector machine Sue E Wells discriminating gas and water the example of figure. Upper primary explanation conclusion gas reservoir, support vector machine determined to be gas-water layer, daily gas production is $1.54 \times 10^{4} \mathrm{~m}^{3} / \mathrm{d}$, daily water production is $15 \mathrm{~m}^{3} / \mathrm{d}$, it has been verified. Lower original interpretation conclusion gas layer, support vector machine determined to be water layer, daily gas production is $0.04 \times 10^{4} \mathrm{~m}^{3} / \mathrm{d}$ after the test gas, daily water production is $12.3 \mathrm{~m}^{3} / \mathrm{d}$, it has been verified. Table 1 is Su54 area use the SVM method to identify gas and water tables to explain the effect can be seen from Table $\mathrm{He}_{8}$ segment discriminant accuracy was 93\%, determine the accuracy of the $\operatorname{Shan}_{1}$ segment is $96.2 \%$.

(1) He8 segment and Shanxi group established - ACOUSTIC cross-plot method, multivariate discriminant analysis, support vector machine, consider many factors, to identify gas reservoir, gas and water and aqueous layers, etc., and its determination in line with rates were $80.8 \%, 79 \%$, 93\%.

(2) Support vector machine to identify the highest accuracy, but discrimination is not easy to understand and debug process modifications, poor applicability, it is recommended to use resistivity-acoustic cross-plot method, multivariate discriminant analysis.

(3) Gas-water identification process, influenced by many factors, should be integrated gas and water a variety of methods to identify and verify the information analyzed by gas test, adjust identification plate.

\section{Acknowledgments}

The authors would like to thank the Qi Zhilin Research Group of Chongqing University of Science and Technology for great help. This Project Supported by Great engineering and technology research 
of the tight gas reservoirs development of China National Petroleum Corporation (2010e-1306) and the National Natural Science Funds of China (Grant No. 41402118)

\section{References}

[1] YANG Hua, WEI Xin-shan.New Progress Achieved by Natural Gas Exploration in Sulige Area[J].Natural Gas Industry, 2007, 27(12):6-11.

[2] DOU Wei-tan,LIU Xin-she,WANG Tao. The origin of formation water and the regularity of gas and water distribution for the Sulige gas field, Ordos Basin [J]. Acta Petrolei Sinica,2010(05):768-772.

[3] Developmen,2008,35(6):664-667.

[4] ZHANG Xin-xin,ZHAO Jing-zhou,MA Jing-hui,etc.Ancient and modern tectonic characteristics of 8th member of Xiashihezi Formation in Sulige Gasfield,Ordos Basin,China and their control effects on gas-water distribution[J]. Journal of Xi'An ShiYou University (Naturnal Science Edition),2011,26 (03):14-20.

[5] ZHU Ya-dong,Wang YUN-cheng,Tong XIAO-hua.Sulige gas field He8 of water-rich layer of gas reservoir identification and genesis [J].Gas Industry,2008,28 (04):46-48.

[6] Hamada G.M.,Nuclear Magnetic Resonance Log Evaluation of Low-Resistivity Sandstone Reservoirs Bt-Passed by Conventional Logging Analysis[J],SPE64406, 2000.

[7] FENG Chun-zhen,LIN Wei-chuan.Geneses of Low Resistivity Gas Zone and Its Log Interpretation Technology in SU Gas Field [J]. Well Logging Technology, 2004,28(6):526-530.

[8] LIU Hong-qi,PENG Shi-Mi, Tang Hong, etc. Research on the distribution characteristics and identifying method of low resistivity gas reservoirs in SUGELI gas field[J]. Southwest Petroleum University,2005,27(1):8-11.

[9] TAN Mao-jin,ZOU You-long,LIU Bing-kai,YANG Xuan,etc. Inversion Simulation of (T2,D) 2D NMR Logging and Analysis of Observation Parameters Effects in Gas-water Model[J]. Well Logging Technology,2011,35(2):130-136.

[10] FU Chen-dong. A new method to determine irreducible water saturation with NMRL data[J]. 2011,25(3): 243-246. 